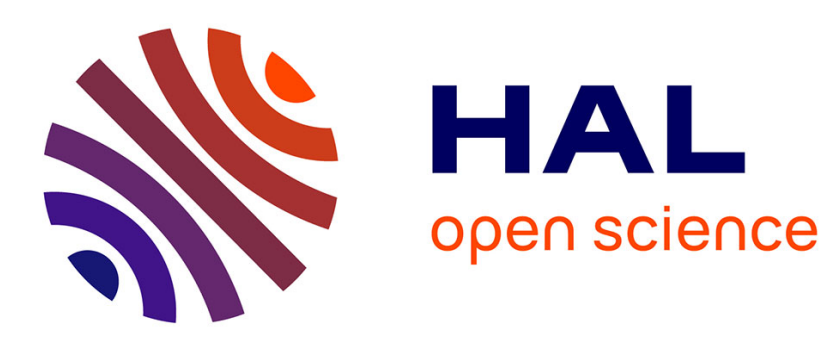

\title{
Study of Shear Viscosity of Amorphous Materials
}

\author{
Y. Hiki, H. Kobayashi, H. Takahashi
}

\section{To cite this version:}

Y. Hiki, H. Kobayashi, H. Takahashi. Study of Shear Viscosity of Amorphous Materials. Journal de Physique IV Proceedings, 1996, 06 (C8), pp.C8-609-C8-612. 10.1051/.jp4:19968130 . jpa-00254562

\section{HAL Id: jpa-00254562 https://hal.science/jpa-00254562}

Submitted on 1 Jan 1996

HAL is a multi-disciplinary open access archive for the deposit and dissemination of scientific research documents, whether they are published or not. The documents may come from teaching and research institutions in France or abroad, or from public or private research centers.
L'archive ouverte pluridisciplinaire HAL, est destinée au dépôt et à la diffusion de documents scientifiques de niveau recherche, publiés ou non, émanant des établissements d'enseignement et de recherche français ou étrangers, des laboratoires publics ou privés. 


\title{
Study of Shear Viscosity of Amorphous Materials
}

\author{
Y. Hiki, H. Kobayashi* and H. Takahashi** \\ Faculty of Science, Tokyo Institute of Technology, Emeritus 39-3-303 Motoyoyogi, Shibuya-ku, Tokyo \\ 151, Japan \\ * National Research Laboratory of Metrology, AIST, MITI, Umezono, Tsukuba 305, Japan \\ ** Applied Physics Group, Faculty of Engineering, Ibaraki University Nakanarusawa, Hitachi 316, Japan
}

\begin{abstract}
Viscoelastic properties of amorphous solids deformed under uniform shear stress were studied using a kind of sandwich method with utilizing a sensitive optical technique. Time-dependent deformation data were analyzed on the basis of a mechanical model of anelasticity plus viscosity. Experiments were performed to determine the temperature dependence of viscosity for several kinds of inorganic glasses and an amorphous polymer below their glass transition temperatures. Activation energies controlling the relaxational viscosity have been determined.
\end{abstract}

\section{INTRODUCTION}

Viscosity is a typical energy dissipating mechanical property of matter, and is closely related to the microscopic motion of atoms and molecules in materials. Especially in solids, such phenomena as movements of various defects in crystalline solids and the flow of atoms or atomic groups in amorphous materials can be investigated through the study of their viscous properties. When the viscosity of a material $\eta$ is due to some relaxation process with a long relaxation time $\tau$, the relation $\eta=\tau M$ holds where $M$ is the elastic modulus [1]. In other words, we can study the internal friction in the limit of zero-frequency by measuring the viscous properties of materials where very slow relaxation phenomena are concerned. The viscosity of solids is, as in the cases of gases and liquids, primarily defined as the shear stress divided by the time derivative of the shear strain. Therefore, the viscosity measurement for solids should be performed under shear deformation. The authors have developed an experimental method for studying the high viscosity solids deformed in the uniform shear mode [2]. We are interested in the study of structural relaxation in glasses below the glass transition $T_{\mathrm{g}}$ where the relaxation should slowly occur. The viscosity measurements have been made for the case of inorganic glasses [2-4], and now the study is extended to the case of amorphous polymers.

\section{EXPERIMENTAL METHOD}

\subsection{Instrumentation}

The viscosity measurement is made by a kind of sandwich method. The upper and the lower faces of a cubic specimen $1 \times 1 \times 1 \mathrm{~cm}$ in sizes are respectively bonded to fixed and movable test plates. A constant lateral load is applied to the movable plate by a weight and bully. The lateral displacement of the movable plate is measured as a function of time by using the HP-5528A laser measurement system, which utilizes the optical heterodyne interferometric method. The nominal sensitivity of the displacement measurement is $10 \mathrm{~nm}$. All the instruments are set on a rigid optical bench. The temperature of the specimen is varied by a small cylindrical furnace set around the specimen, and is controlled by a PID (proportional integral and differential) unit. The temperature constancy is better than $0.1^{\circ} \mathrm{C}$ during an experimental run, and the temperature uniformity in the specimen is, for example, better than $1.5^{\circ} \mathrm{C}$ at $90^{\circ} \mathrm{C}$. As for the bonding materials between the specimen and test plates, Aron-Alpha \#201 (Toagosei Co., Ltd., Tokyo) or Sauereisen No. P-1 (Sauereisen Cement Co., Ltd., Pittsburg) are used. It has been shown that the deformation mode of the specimen is almost uniform pure shear in the present experimental conditions [2]. 


\subsection{Data analysis}

Examples of the raw data for two kinds of glasses are illustrated in Figure 1 where the displacement of the upper test plate is shown as a function of time when a load is applied and then removed. The time dependence of the displacement can be divided into four stages: an instantaneous increase (I) followed by a gradual increase (II) when the load is applied; and an instantaneous decrease (III) followed by a gradual decrease (IV) after the load is removed. Stages (I) and (III) are due to the elastic deformation of the specimen; while a viscoelastic time-dependent deformation of the specimen is observed in stages (II) and (IV), which is the object of our present interest. It is further observed that in stage (II) the displacement firstly increases exponentially and then linearly with time, and in stage (IV) the displacement exponentially decreases. These behaviors are well represented by a combination of anelasticity (mechanical relaxation, short relaxation time) plus viscosity (long relaxation time). By using a mechanical model, a series connection of the Zener's standard linear solid plus a viscous dashpot, the data can be analyzed for obtaining the anelastic relaxation time, the anelastic modulus, and the viscosity of the specimen [2]. By using such an analysis, the anelasticity and the viscosity are separated, and the viscosity can be determined more accurately compared with usual methods in which the anelasticity is ignored. In the present study, only the viscosity is noted.

\section{RESULTS AND DISCUSSION}

Viscosity measurement was performed for several kinds of inorganic glasses and also for amorphous polymers below their glass transition temperature $T_{\mathrm{g}}$. Low- $T_{\mathrm{g}}$ materials were selected as specimens because of restrictions of measuring apparatus. The displacement vs time data as shown in Figure 1 were analyzed, and the viscosity values were obtained as functions of temperature. The measurements were made from room temperature up to a temperature as close as possible to the glass transition. The measured data of temperature dependence of viscosity $\eta$ are collected in Figure 2 for various amorphous materials, where $\log \eta$ values are plotted against inverse absolute temperature normalized by the glass transition $T_{\mathrm{g}} / T$. The data are illustrated for four materials:

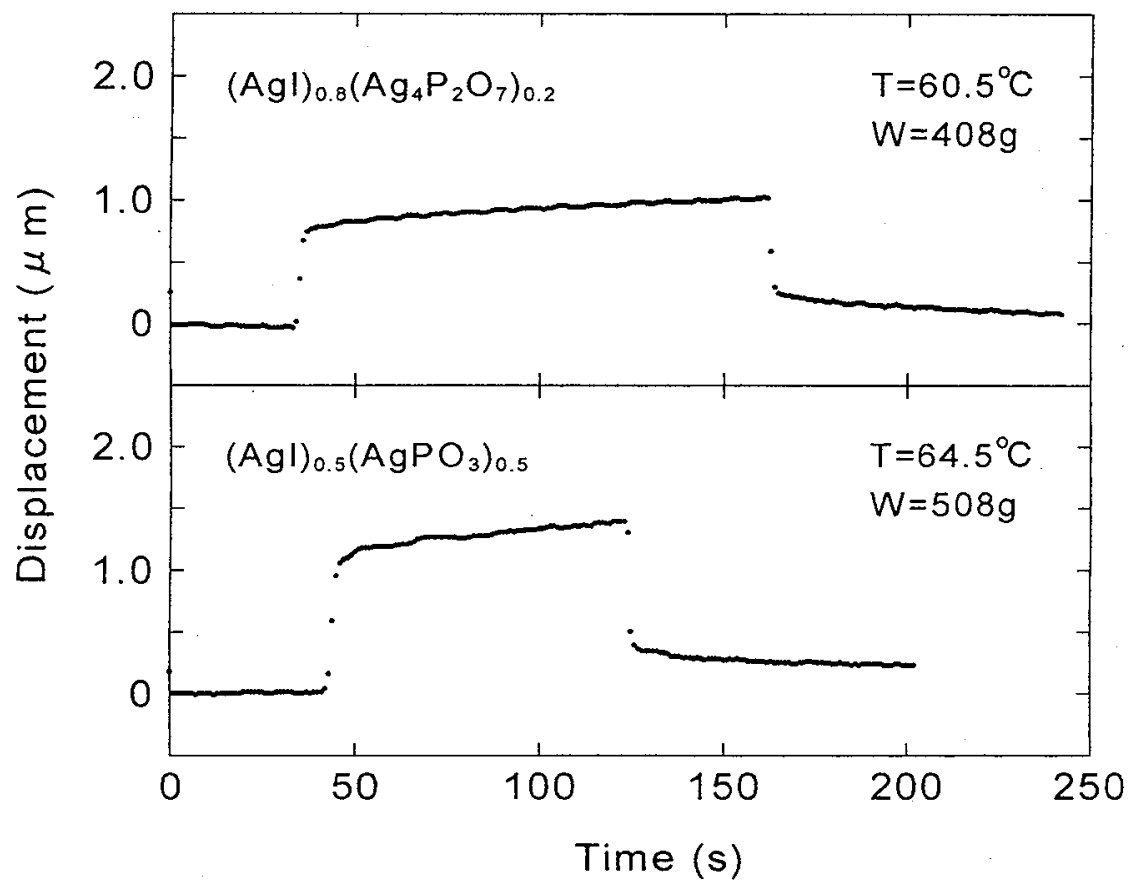

Figure 1: Displacement vs time for two kinds of glasses at temperature $T$ when constant load $W$ is applied and then removed. 
(a) Molybdate glass (AgI $)_{0.7}\left(\mathrm{Ag}_{2} \mathrm{MoO}_{4}\right)_{0.3} \quad\left(T_{\mathrm{g}}=335 \mathrm{~K}\right)$,

(b) Pyrophosphate glass ( $\mathrm{AgI})_{0.8}\left(\mathrm{Ag}_{4} \mathrm{P}_{2} \mathrm{O}_{7}\right)_{0.2}\left(T_{\mathrm{g}}=353 \mathrm{~K}\right)$

(c) Metaphosphate glass $(\mathrm{AgI})_{0.5}\left(\mathrm{AgPO}_{3}\right)_{0.5} \quad\left(T_{\mathrm{g}}=362 \mathrm{~K}\right)$,

(d) Polystyrene $-\mathrm{CH}_{2} \mathrm{CH}\left(\mathrm{C}_{6} \mathrm{H}_{5}\right)-\quad\left(T_{\mathrm{g}}=366 \mathrm{~K} ; M_{\mathrm{n}}=7.7, M_{\mathrm{w}}=18.1\left(10^{4}\right)\right)$.

Glass transition temperatures $T_{\mathrm{g}}$ are determined by the DTA (differential thermal analysis) method for the same specimens used in the viscosity experiment, and the number-averaged and weightaveraged molecular weights, $M_{\mathrm{n}}$ and $M_{\mathrm{w}}$, of the polymer are determined by a chromatography.

The viscosity measurement was limited to the range shown in the figure. At lower temperatures, the viscosity becomes very large and the deformation of specimen is too small, making reliable measurement impossible. At higher temperatures, the deformation occurs too rapidly even when the smallest load is applied, and it becomes difficult to carry out the measurement. The range of viscosity measurable with our apparatus is $\eta=10^{8}-10^{13} \mathrm{~Pa} \cdot \mathrm{s}$. Although the temperature range of measurement is rather narrow, we observe a great change in viscosity.

In the data shown above the following characteristics can be seen:

(1) The viscosity markedly increases with decreasing temperature near the glass transition $T_{\mathrm{g}}$, and here $\log \eta \propto T^{-1}$ for all materials (a)-(d).

(2) The rapid increase of viscosity with decreasing temperature is weakened in lower temperature range for materials (c) and (d).

(3) The viscosity value at $T_{\mathrm{g}}$ is around $10^{7}-10^{8} \mathrm{~Pa} \cdot \mathrm{s}$ for materials (a)- (c), and is somewhat smaller for material $(d)$.

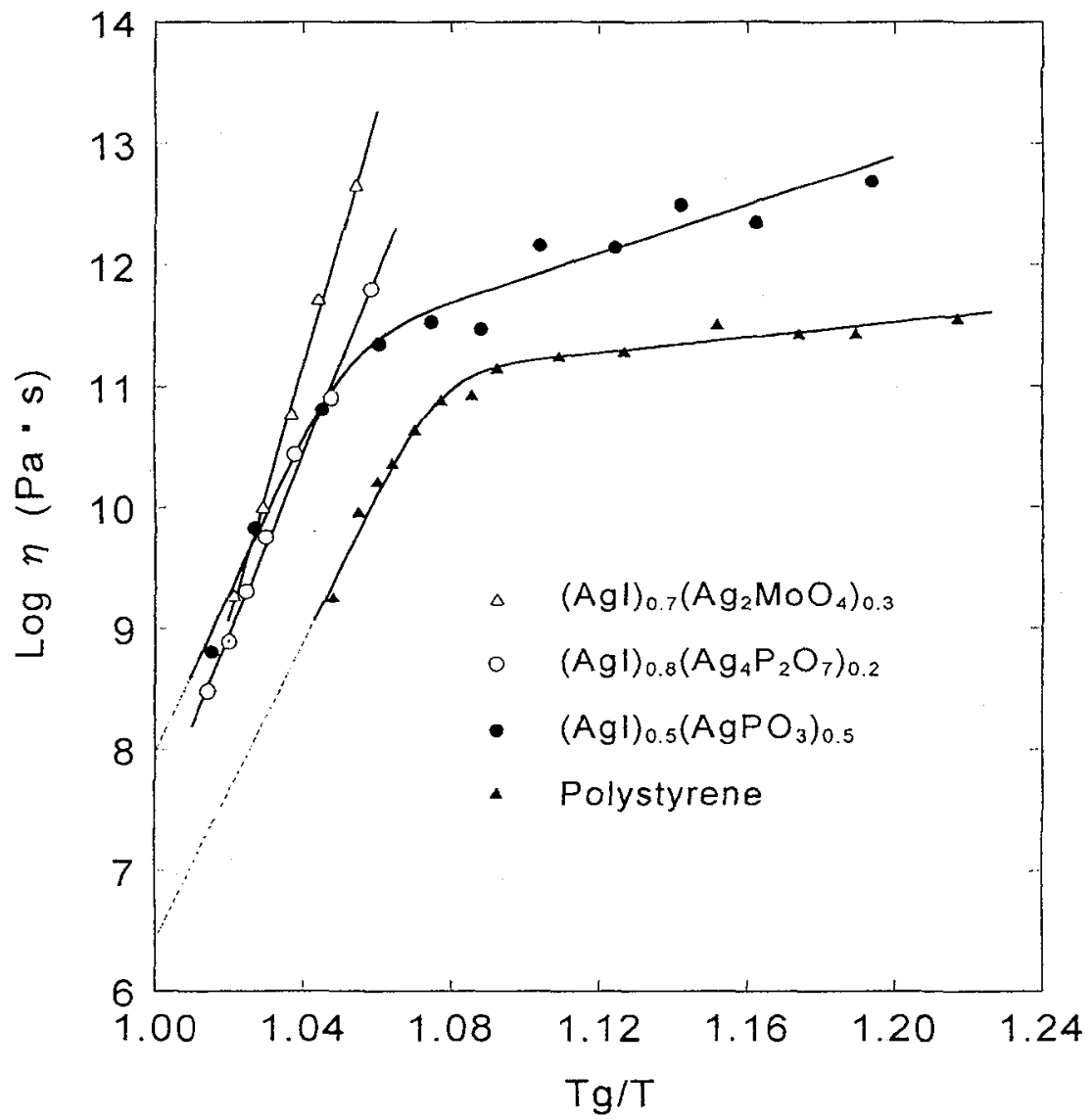

Figure 2: Temperature dependence of viscosity $\eta$ for amorphous materials. Straight lines and curves are results of parameter fits to determine the activation energies. 
These features will be considered in the following. The commonly observed rapid change of the viscosity close to $T_{\mathrm{g}}$ can be a thermal activation process with a single relaxation time $\tau$ and a definite activation energy $E$. In the case of materials (c) and (d), another activation process with a relaxation time $\tau^{\prime}$ and an activation energy $E^{\prime}$ coexists at lower temperatures. In the latter case, the relation $(1 / \eta) \propto$ const. $(1 / \tau)+$ const. $\left(1 / \tau^{\prime}\right)$ is assumed. The Arrhenius relation is considered between the relaxation time and the activation energy. Using the experimental results the activation energies were determined for four materials as

(a) Molybdate glass: $E=673 \mathrm{~kJ} / \mathrm{mol}$,

(b) Pyrophosphate glass: $E=505 \mathrm{~kJ} / \mathrm{mol}$,

(c) Metaphosphate glass: $E=463 \mathrm{~kJ} / \mathrm{mol} ; E^{\prime}=68 \mathrm{~kJ} / \mathrm{mol}$,

(d) Polystyrene: $E=449 \mathrm{~kJ} / \mathrm{mol} ; E^{\prime}=22 \mathrm{~kJ} / \mathrm{mol}$.

In Figure 2, the straight lines for (a) and (b) and the curves for (c) and (d) are fitted ones where the method of the above analysis is used. Note that the two-activation energy fit seems to work reasonably well for the latter two materials.

It is apparent that there is a great difference between the viscosity vs temperature behaviors for two groups of materials: (a), (b) and (c), (d). The temperature dependence of viscosity is considered to be due to structural relaxation of the materials, and the difference between molecular structures in these two kinds of materials should be noted.

(a) Molybdate glass is composed of isolated $\mathrm{MoO}_{4}$ tetrahedral molecular units, and the units are randomly distributed in the material.

(b) Pyrophosphate glass is composed of combined two $\mathrm{PO}_{4}$ tetrahedrons, and the units are isolated with each other and randomly distributed.

(c) Metaphosphate glass is composed of long chains of $\mathrm{PO}_{4}$ tetrahedrons which share two $\mathrm{O}$ atoms.

(d) Polystyrene is composed of long - C- chains.

Namely, the characteristic of the second group materials, (c) and (d), is the existence of long molecular chains as the glass forming network. In these materials, the relaxation observed at low temperatures with small activation energies can be due to the existing molecular chains. The molecules or molecular units on the chains may not be in stable states and a relaxation to more stable states on the chain possibly occurs. Meanwhile, all materials (a)-(d) show the relaxation with high activation energy near the glass transition temperature. This relaxation is considered to be essentially related with the glass transition phenomenon where severe structural changes are occurring.

The magnitude of the viscosity of glasses measured by the present experimental method is finally considered. The viscosity values are $\eta=10^{6}-10^{8} \mathrm{~Pa} \cdot \mathrm{s}$ at the glass transition $T_{\mathrm{g}}$. The viscosity of some of the glasses, $(\mathrm{AgI})_{0.5}\left(\mathrm{AgPO}_{3}\right)_{0.5}$, was also measured using other experimental methods, the rotation disk viscometer method. This method is well established for measuring the viscosity of low-viscosity materials in a pure shear mode, and the measurable range of the viscosity is $10^{-1}-10^{8} \mathrm{~Pa} \cdot \mathrm{s}$. Using this method the shear viscosity measurements were performed from higher temperatures down to the glass transition. The two kinds of data, from the rotation viscometer and our sandwich method, are quite smoothly related [2]. This is a clear experimental certification that the shear viscosity can be measured at the high viscosity region with our experimental method. The viscosity of glasses at $T_{\mathrm{g}}$ is usually said to be of the order of $10^{12} \mathrm{~Pa} \cdot \mathrm{s}[5,6]$. However, almost all of the cited data have been determined by another method of viscosity measurement, the beam bending method. In this method, the deformation mode is nat so simple as in the sandwich method and rotation method [2]. It is considered that the true shear viscosity, which is physically most meaningful, cannot be measured by the beam bending method, but can be measured by the simple shear mode method as used by the present authors.

\section{References}

[1] Landau L.D. and Lifshits E.M., Theory of Elasticity, translated by Sykes J.B. and Reid W.H. (Pergamon Press, Oxford, 1963).

[2] Kobayashi H., Hiki Y. and Takahashi H., J. Appl. Phys., July (1996) in press.

[3] Hiki Y., Takahashi H. and Kobayashi H., Solid State Ionics 53-56 (1992) 1157-1163.

[4] Hiki Y, Takahashi H. and Kobayashi H., J. Alloys \& Compd. 211/212 (1994) 333-336.

[5] Cusack N.E., The Physics of Structurally Disordered Matter (Adam Hilger, Bristol, 1987).

[6] Gutzow I. and Schmelzer J., The Vitreous State (Springer, Berlin, 1995). 